ANL -6653

Mathematics and

Computers

(TID-4500, 18th Ed.)

AEC Research and

Development Report

ARGONNE NATIONAL LABORATORY

9700 South Cass Avenue

Argonne, Illinois

\title{
TRANSIENT ANALYSIS OF TWO-PHASE NATURAL-CIRCULATION SYSTEMS
}

by

R. P. Anderson, * L. T. Bryant, ** J. C. Carter, * and J.F. Marchaterre*

* Reactor Engineering Division

**Applied Mathematics Division

December 1962

Operated by The University of Chicago

under

Contract W-31-109-eng-38

with the

U. S. Atomic Energy Commission 


\section{DISCLAIMER}

This report was prepared as an account of work sponsored by an agency of the United States Government. Neither the United States Government nor any agency Thereof, nor any of their employees, makes any warranty, express or implied, or assumes any legal liability or responsibility for the accuracy, completeness, or usefulness of any information, apparatus, product, or process disclosed, or represents that its use would not infringe privately owned rights. Reference herein to any specific commercial product, process, or service by trade name, trademark, manufacturer, or otherwise does not necessarily constitute or imply its endorsement, recommendation, or favoring by the United States Government or any agency thereof. The views and opinions of authors expressed herein do not necessarily state or reflect those of the United States Government or any agency thereof. 


\section{DISCLAIMER}

Portions of this document may be illegible in electronic image products. Images are produced from the best available original document. 
TABLE OF CONTENTS

Page

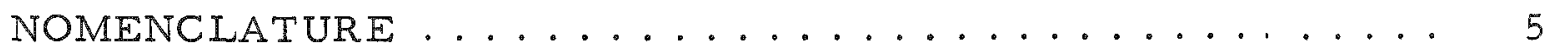

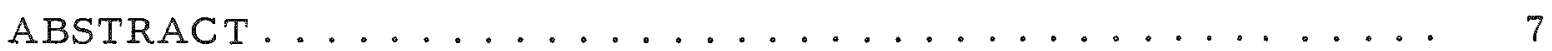

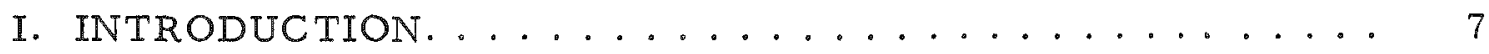

II. THE TIME - AND SPACE-DEPENDENT MASS, ENERGY, AND MOMENTUM EQUATIONS................. 11

III. ANALOG COMPUTER CONSIDERATIONS .......... 18

A. Definition of Machine Variables............. 18

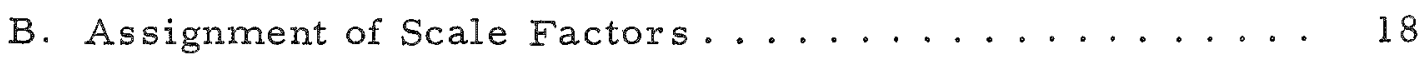

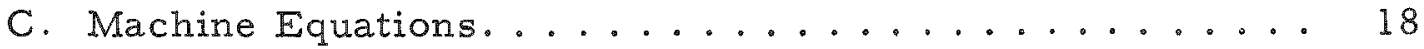

D. Values of Constants and Initial Conditions ........ 20

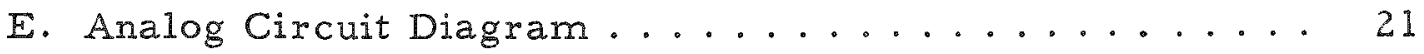

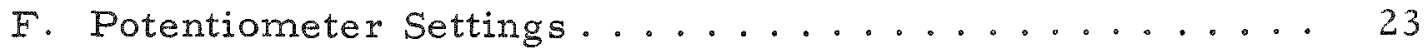

IV. COMPARISON OF MODEL PERFORMANCE WITH

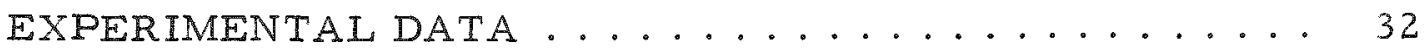

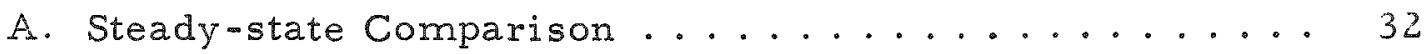

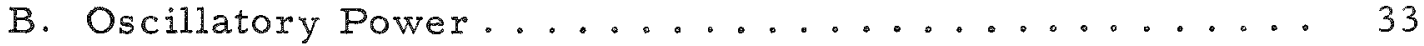



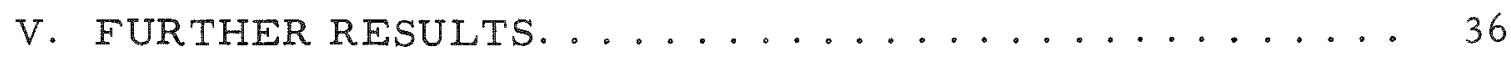

VI. GENERAL DISCUSSION AND CONCLUSIONS ......... 38

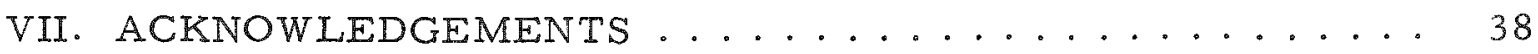

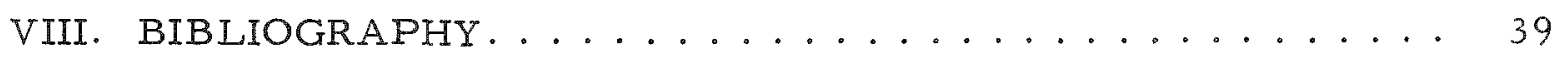




\section{LIST OF FIGURES}

No.

Title

Page

1. Boiling Loop ......................... 8

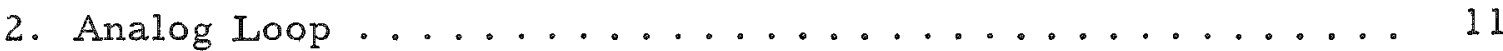

3. Variation of Mean Density in the Vertical Boiling Channel to Liquid Density for Slip Ratio of Unity..............

4. Linear Deviation of Steam Volume Fraction in the Test

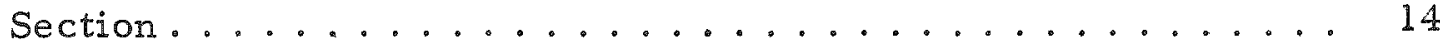

5. Correlation of Velocity Ratios as a Function of Froude Number and the Volumetric Flow Rate of Each Phase...... 15

6. Mean Two-phase Friction Multiplier vs. Steam Volume

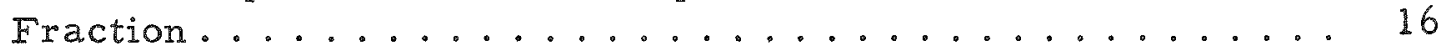

7. Analog Circuit Diagram................. 22

8. Comparison of Experimental Data with Analog Model

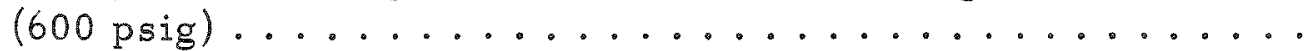

9. Comparison of Experimental Data with Analog Model

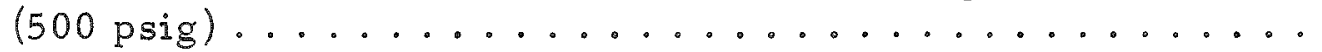

10. Comparison of Experimental Data with Analog Model

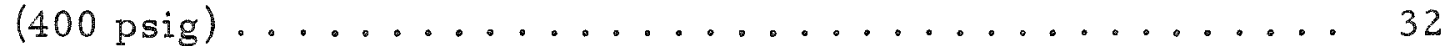

11. Transient Comparison between Analog Model and Experimental Measurements..................

12. Comparison of Predicted and Measured Power at the

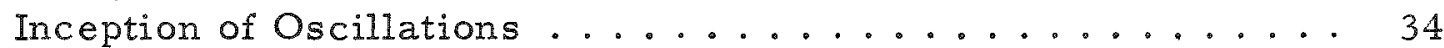

13. Alternate Models of Velocity Ratio as a Function of Power ... 36

14. Dependence of Unstable Power on Riser Time Lag...... 37 


\section{LIST OF TABLES}

No.

Title

Page

1. Values of Constants and Initial Conditions - 1-in. Geometry,

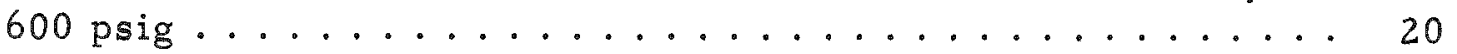

2. Values of Constants and Initial Conditions - 1-in. Geometry,

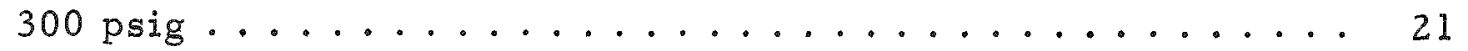

3. Analog Potentiometer Settings - 1-in. Geometry, 600 psig . . . 24-27

4. Necessary Changes in Analog Potentiometer Settings to Change from 1 -in. Geometry, $600 \mathrm{psig}$, to 1 -in. Geometry,

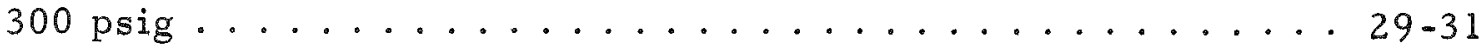

5. Comparison of Unstable Power Level - 1-in. Geometry,

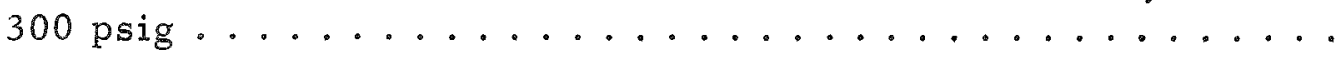




\section{NOMENCLATURE}

\begin{tabular}{|c|c|}
\hline A & area, $\mathrm{ft}^{2}$ \\
\hline $\mathrm{C}_{\mathrm{i}}$ & constants in the slip correlation $(i=1,2,3)$ \\
\hline $\mathrm{C}_{4}$ & constant for fraction of steam volume \\
\hline $\mathrm{D}$ & diameter, ft \\
\hline f & friction factor \\
\hline $\mathrm{g}$ & gravitational acceleration, $\mathrm{ft} / \mathrm{sec}^{2}$ \\
\hline $\mathrm{h}$ & enthalpy, BTU/1b \\
\hline$K$ & correction for friction factor \\
\hline$\ell$ & length, ft \\
\hline$Q$ & powero, kw \\
\hline$S$ & vapor-liquid velocity ratio (slip ratio) \\
\hline $\mathrm{T}$ & time lag, sec \\
\hline$V_{0}$ & superficial velocity, $\mathrm{ft} / \mathrm{sec}$ \\
\hline W & flow rate, $1 \mathrm{~b} / \mathrm{sec}$ \\
\hline $\mathrm{x}$ & quality, Ib vapor/1b two-phase fluid \\
\hline $\mathrm{Z}$ & vertical distance, ft \\
\hline$\alpha$ & fraction of steam volume \\
\hline$\rho$ & density, Ib/ft $t^{3}$ \\
\hline$T$ & time, sec \\
\hline
\end{tabular}

Subscripts

D downcomer

$f$ liquid

$g$ gas

in inlet

$m$ makeup

$R$ riser

$T$ test section 
Numbers $1-4$ denote locations in the loop:

1 - top of the riser

2 - test section inlet

3 - boiling boundary

4 - riser inlet

Superpost bar indicates mean 


\title{
TRANSIENT ANAIYSIS OF TWO-PHASE NATURAL-CIRCULATION SYSTEMS
}

by

R. P. Anderson, L. T. Bryant, J.C. Carter, and J. F. Marchaterre

\begin{abstract}
The design of high-performance natural-circulation boiling systems requires that the behavior of the systems be characterized under transient conditions. In order to accomplish this, the time - and space-dependent continuity, energy, and momentum equations for a natural-circulation system are written.

This publication presents a technique for solving the equations of a natural-circulation system. The solutions are compared with experimental results at various pressures with two geometries in boiling water systems.

The solutions meet the established criteria. The analog model is useful for predicting the behavior of two-phase natural-circulation systems during transients. The model accurately predicts the point at which such systems exhibit oscillatory behavior.

The results were found to be sensitive to the vapor liquid velocity ratio (slip ratio) used in the computation. The velocity ratio correlation used in the model is presented. All computations, circuits, and operating information necessary to duplicate the experiment are given.
\end{abstract}

\section{INTRODUCTION}

The use of boiling for heat removal from high-performance nuclear reactor systems has focused attention on the problems of predicting the transient behavior of both forced-and natural-circulation two-phase sys tems. A number of investigators (Ref. 1-6) have made studies of the possible mechanisms which cause oscillations in natural-circulation systems. 
Unstable behavior is one of the main power-limiting factors in a boiling water reactor. Similar unstable behavior has been noted in reactorsimulating test loops with constant power input. In the belief that the oscillations observed in test loops were a primary contributing factor for, if not the sole cause of, reactor oscillations, experimental study of the dynamic behavior of two-phase natural-circulation loops has been carried out over the past two years. A typical test loop is shown in Fig. 1.

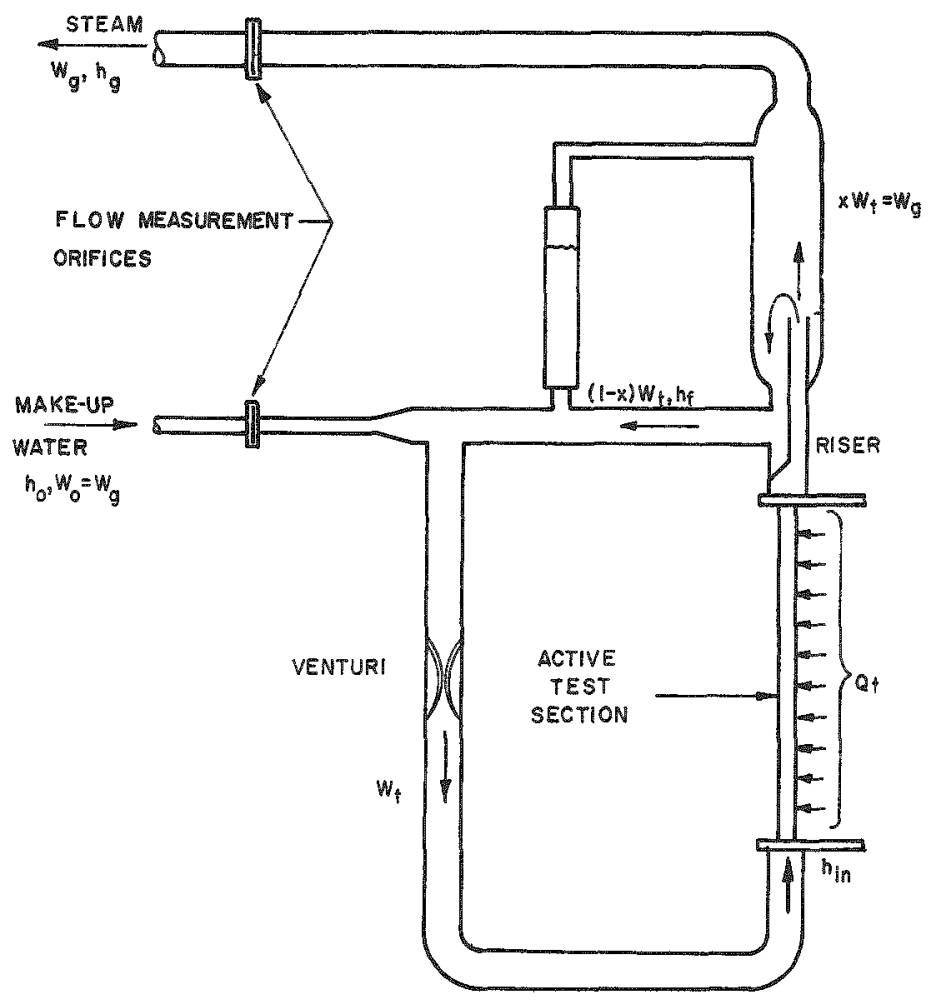

Fig. 1. Boiling Loop

In the initial stages of this investigation, a quick-response optical recording system was installed. This system was used to record: temperature (measured with very small bead thermocouples) at the makeup point and various points throughout the downcomer, including the test section inlet; pressure drop (measured with a strain-gage transducer) across the orifices measuring steam and makeup flow and the venturi measuring total flow; the output signal from turbine flow meters in the in let and for some of the tests in the outlet of the test section; steamvolume-fraction indication from a $\gamma$-ray-attenuation measuring device; power for the series of runs where the power was oscillated. Simultaneously, the following steady-state measurements were recorded: system pressure; makeup temperature; downcomer temperature; inlet temperature: pressure drop across the various flow-measuring devices; pressure drop across the individual segments of the loop and power. 
used:

During the course of this experiment the following geometries were

1. 1.252-cm-ID test section and riser - unrestricted;

2. $1.580-\mathrm{cm}-$ ID test section and riser - unrestricted:

3. 2.381 -cm-ID test section and riser - unrestricted;

4. 1.252-cm-ID test section, $1.580-\mathrm{cm}$ riser - unrestricted:

5. 2.381-cm-ID test section, $1.580-\mathrm{cm}$ riser - unrestricted;

6. $2.381-\mathrm{cm}-$ ID test section and riser - restricted:

a. large riser restriction only:

b. small riser restriction only:

c. large downcomer restriction only:

d. small downcomer restriction only:

e. large riser restriction, small downcomer restriction:

f. small riser restriction, large downcomer restriction.

The large and small riser restrictions were orifices with inside diameters of $1.19 \mathrm{~cm}$ and $1.67 \mathrm{~cm}$. The large and small downcomer restrictions were crossover valve settings corresponding to flow reductions of $10 \%$ and $22 \%$. In all cases the test section length was $0.914 \mathrm{~m}$ and the riser length was $0.762 \mathrm{~m}$.

The series of different operating pressures for each geometry usually included $300,400,500$, and 600 psig. At a given operating pressure and geometry the power was raised in increments, with a stabilizing period between the time when the powex was increased and the time when the measurements were taken. For each run a fast and a slow trace of the transient instrumentation were taken, and the steady-state measurements were recorded. The loop was termed unstable if steady oscillations were detected in the measurement of the total recirculation flow. In some cases this was not an abrupt change with the loop going from stable to unstable during one incremental change of power, but instead showed an increasing lack of stability over a range of powers. For certain of the above pressure and geometry combinations the power was sinusoidally varied at one -half, one, and two cycles per second, and the resultant parameter variation was recorded by the instrumentation for measuring transients.

Before the results of these tests were completely reduced and tabulated, it was believed that a large-enough backlog of experimental data wexe available to furnish an adequate comparison with an attempted analytical model. 
Iwo approaches to the problem of stability prediction have been tried:

1. The cause of the oscillation is assumed to be an isolated phenomenon and the phenomenon is studied in detail.

2. Solutions of the general time-dependent equations of the system are studied by either analytical solutions of linearized equations or computer solutions of lumped-parameter models.

With the experimental information derived, another analytical attempt was justified. It is reasonable that any model must meet three requirements:

1. The model must provide an accurate steady-state calculation of the recirculation rate and vapor volume fraction for various power inputs:

2. It must reproduce the experimental transient behavior during varying power inputs; and

3. The model must accurately predict the inception of oscillations in a natural-circulation system without adjusting constants between analog calculations. 
II. THE TIME-AND SPACE-DEPENDENT MASS, ENERGY, AND MOMENTUM EQUATIONS

The loop is divided into four increments as shown in Fig. 2. Positions $1,2,3$, and 4 correspond to

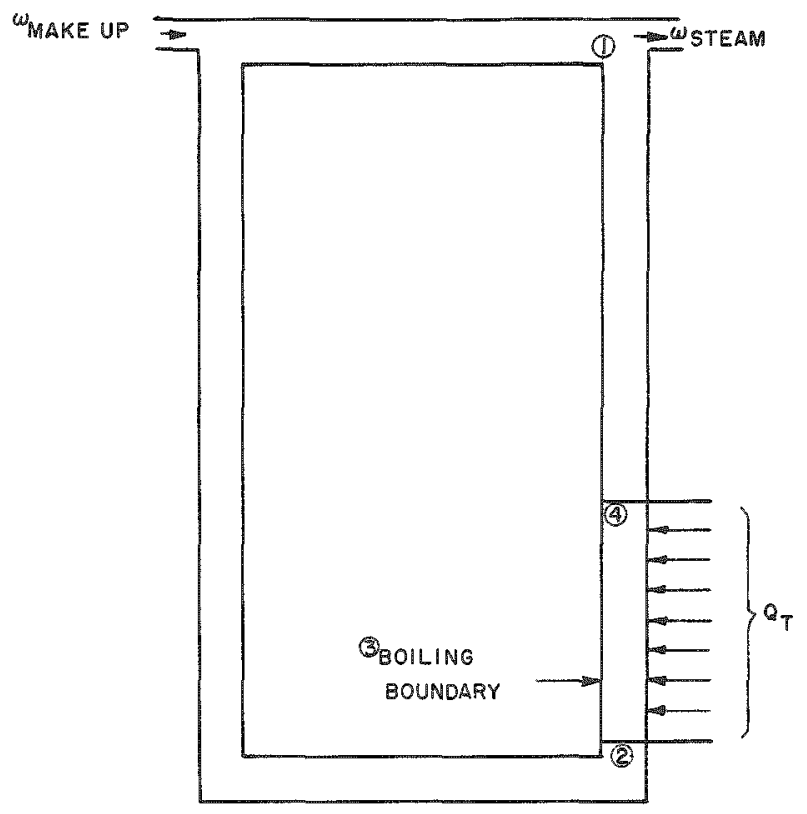

Fig. 2. Analog Loop the top of the riser, inlet to the test section, net boiling boundary, and the bottom of the riser, respectively.

The system is subject to geometric constraints and the equations for conservation of mass, energy, and momentum are written for each increment.

The application of the law of conservation of mass to the twophase segments of the loop results in an equation in which the rate of change of the mass in an increment is equal to the difference in inlet and exit mass flow rates.

In the boiling segment with all water inlet and two-phase exit

conditions, the equation becomes

$$
\frac{d\left(A_{T} \ell_{3-4} \bar{\rho}_{3-4}\right)}{d \tau}=W_{f_{3}}-W_{f_{4}}-W_{g_{4}}
$$

In the riser,

$$
\frac{d\left(\bar{\rho}_{4-1} A_{R} \ell_{4-1}\right)}{d \tau}=W_{f_{4}}+W_{g_{4}}-W_{f_{1}}-W_{g_{1}}
$$

The total mass flow across any plane is equated to the mass of the vapor and the mass of the liquid flowing across the plane. The resultant equation is an altered form of the well-known slip-ratio equation:

$$
S=\left(\frac{x}{1-x}\right) \quad\left(\frac{1-\alpha}{\alpha}\right) \frac{\rho_{f}}{\rho_{g}} .
$$

This equation is used to determine liquid flow past a point when gas flow, steam volume fraction, and vapor-liquid velocity ratio at the point are known. Thus, at the exit plane of the test section, 
$W_{f_{4}}=\left[\frac{\rho_{f}}{\rho_{g} S}\right] \frac{W_{g_{4}}}{\alpha_{4}}-\left[\frac{\rho_{f}}{\rho_{g} S}\right] W_{g_{4}}$.

In steady state the nonboiling length can be calculated from an energy balance:

$$
\left(b_{2-3}\right)_{\text {st.st. }}=\frac{W_{f_{2}}\left(h_{f}-h_{2}\right)}{Q_{T} / l_{T}} .
$$

For the time-dependent model, a pseudo-steady-state length was calculated continuously, by the use of instantaneous values of flow rate and inlet enthalpy in the above equation. At any time $t$, the difference between the pseudo-steady-state value and the actual value is assumed to be directly proportional to the time derivative of the length. The derivative is also as sumed to be inversely proportional to the transport time through the nonboiling length, $\mathrm{T}_{2-3}$, where

$$
\mathrm{T}_{2-3}=l_{2-3} \mathrm{~A}_{\mathrm{T}}^{\rho_{\mathrm{f}}} / \mathrm{W}_{\mathrm{f}_{2}}
$$

thus,

$$
\frac{d\left(l_{2-3}\right)}{d T}=\frac{\left(l_{2-3}\right) \text { pseudo st.st. }-l_{2-3}}{T_{2-3}}
$$

Combining equations 4,5 , and 6 and simplifying:

$$
\frac{d\left(l_{2-3}\right)}{d \tau}=\left(\frac{l_{T}}{A_{T} \rho_{f}}\right) \frac{W_{f_{2}}^{2}\left(h_{f}-h_{2}\right)}{Q_{T} l_{2-3}}-\frac{W_{f_{2}}}{A_{T} \rho_{f}}
$$

Similarly, energy conservation in the boiling part of the test section leads to the equation for variation of exit gas flow rate in terms of a pseudosteady-state gas flow rate:

$$
\left(W_{g_{4}}\right)_{\text {pseudo st.st. }}=Q_{T} \frac{l_{3-4}}{\ell_{T}}\left(\frac{1}{h_{f g}}\right),
$$

and time lag through the boiling section,

$$
T_{3-4}=l_{3-4} \bar{A}_{g_{3-4}} \rho_{g} / \bar{W}_{g_{3-4}}
$$

resulting in

$$
\frac{d\left(W_{g_{4}}\right)}{d T}=\frac{Q_{T} W_{g_{4}}}{2 h_{f g} \ell_{T} \rho_{g} A_{g}}=\frac{W_{g_{4}}^{2}}{2 A_{g} \rho_{g} \ell_{3-4}}
$$


In increments where external energy transport is zero, the energyconservation equations are in the form of simple time-lag equations with the exit parameters lagging the inlet parameter by the transit time through the increment.

The inlet temperature is calculated from a heat balance of the make up point and lagged by the transit time to the inlet:

$$
\begin{aligned}
& W_{f_{2}} h_{2}=h_{f}\left(W_{f_{2}}-W_{g_{4}}\right)+h_{m} W_{g_{4}} ; \\
& T_{1-2}=b_{1-2} \rho_{f} A_{D} / W_{f_{2}} .
\end{aligned}
$$

The exit vapor flow from the riser is lagged by a variable time lag based on the mean velocity of the riser:

$$
\mathrm{T}_{4-1}=\mathrm{A}_{\mathrm{R}} \ell_{\mathrm{R}} \bar{\rho}_{4-1} / \overline{\mathrm{W}}_{4-1}
$$

The mean velocity in the riser as used in the above equation and the momentum equation is based on the mean value of inlet and exit mass flow rates:

$$
\bar{W}_{4-1}=\frac{1}{2}\left(W_{f_{4}}+W_{g_{4}}+W_{f_{1}}+W_{g_{1}}\right)
$$

Similarly,

$$
\bar{W}_{3-4}=\frac{1}{2}\left(W_{f_{3}}+W_{g_{4}}+W_{f_{4}}\right) \text {. }
$$

A linear variation is assumed for steam void fraction in the riser:

$$
\bar{a}_{4-1}=\frac{1}{2}\left(a_{4}+a_{1}\right)
$$

The mean void fraction in the boiling portion, however, is adjusted to account for the nonlinear variation of void with the variation of quality up the test section. Figure 3 shows variation of $\bar{p}$ as a function of exit void fraction. Figure 4 shows a cross plot from Fig. 3 to give average voids in terms of mean density. The proper coefficient, $\mathrm{C}_{4}$, for variation around the expected region of interest is obtained from Fig. 4, where

$$
\alpha_{4}=C_{4}-C_{4} \frac{\bar{\rho}_{3-4}}{\rho_{f}} .
$$




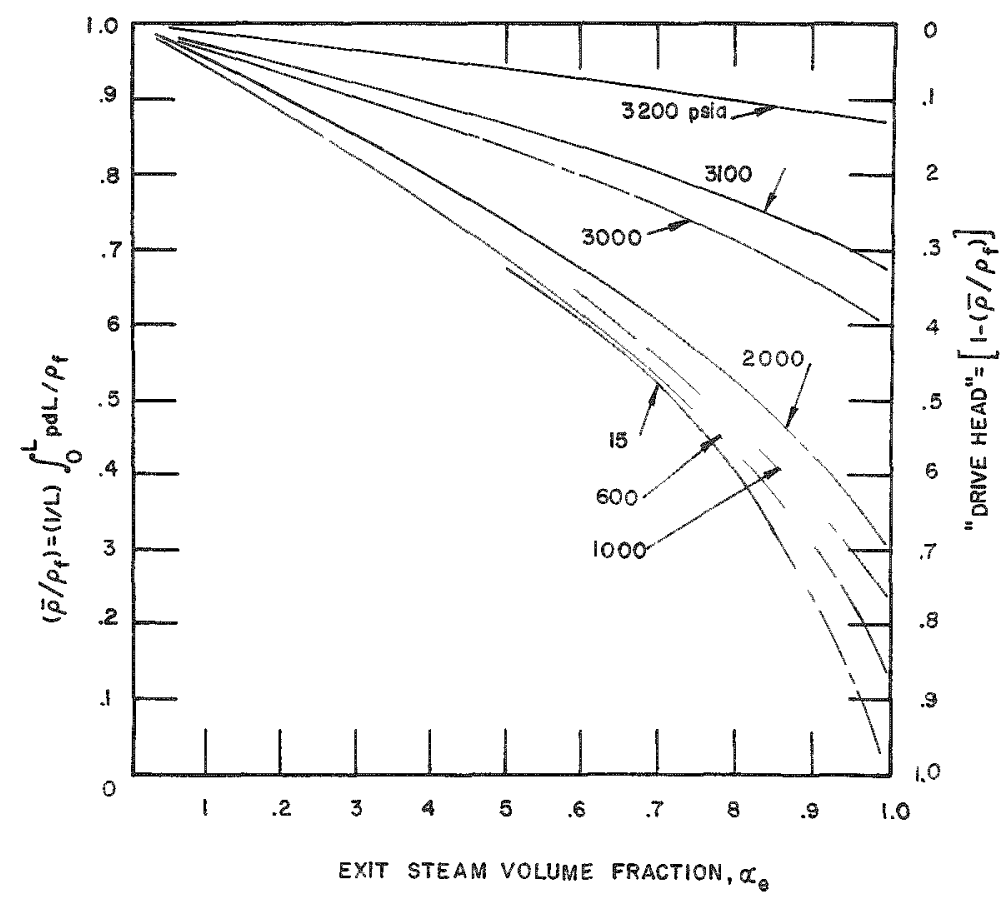

Fig. 3. Variation of Mean Density in the Vertical Boiling Channel to Liquid Density for Slip Ratio of Unity

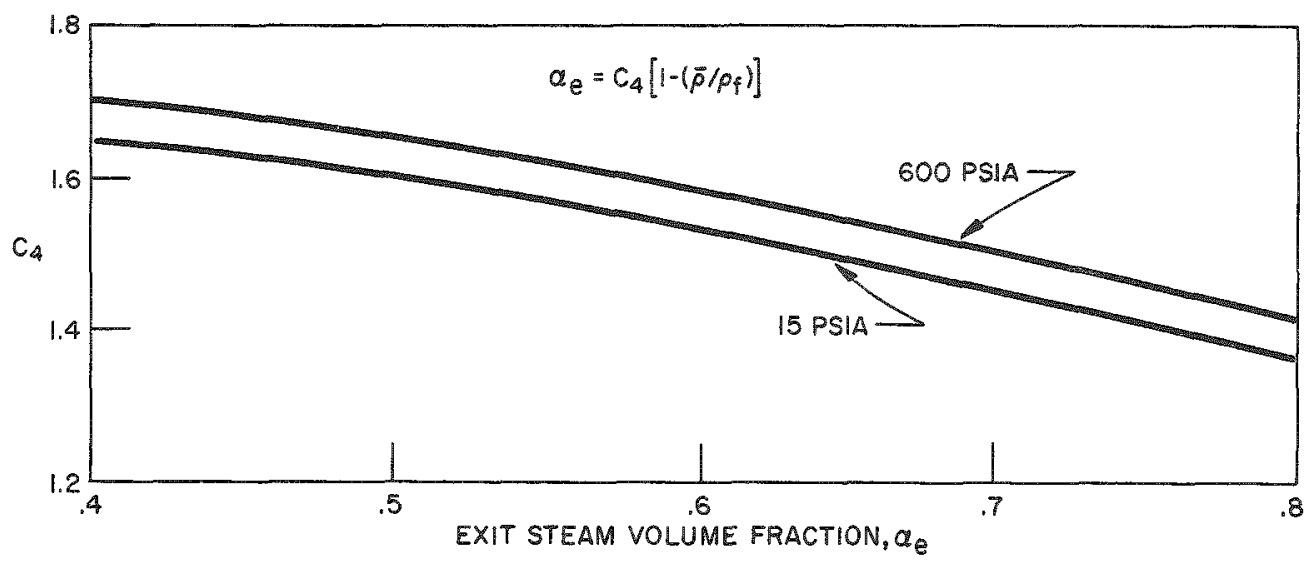

Fig. 4. Linear Deviation of Steam Volume Fraction in the Test Section

The vapor-liquid velocity ratio (slip ratio) is a very important parameter in the model. For any given pressure and geometry, this ratio is represented by an equation of the form

$$
S=C_{1}+\left(C_{2}-C_{3} V_{0}\right) x
$$

where $V_{0}$ is the superficial velocity based on the fluid flowing as liquid through the total cross section, and $x$ is quality. Here, $C_{1}, C_{2}$, and $C_{3}$ are 
evaluated by means of a slip-ratio correlation in terms of the dimensionless quantities $\left\{\left(\frac{x}{1-x}\right) \frac{\rho_{f}}{\rho_{g}}\right\}$ and the Froude number, $V_{0 / g D}^{2}$. Figure $5(7)$ shows this correlation, which does not have the linear form of the above slip equation. It was linearized for the high-quality regions where the loop would be expected to go unstable.

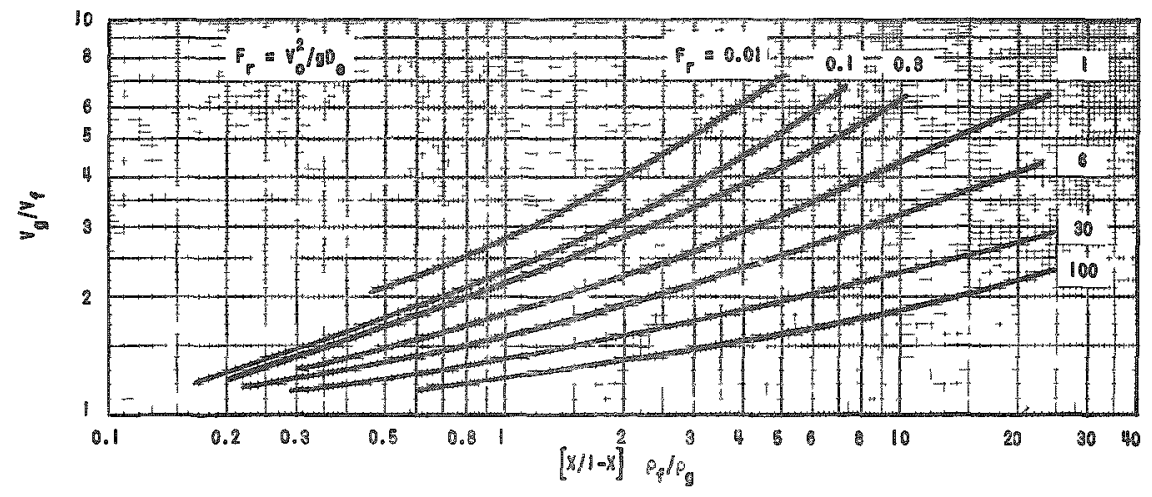

Fig. 5. Correlation of Velocity Ratios as a Function of Froude Number and the Volumetric Flow Rate of Each Phase

In the single-phase portion of the loop. the rate of change of momentum is equated to the net unbalance of the friction, gravitational head, and pressure-drop forces:

$\frac{d\left(W_{i_{2}}\right)}{d \tau}=\left(p_{1}-p_{2}\right) \frac{A_{D} g C}{l_{1-2}}-(f+K) \frac{\left(W_{f_{2}}\right)^{2}}{2 A_{D} D_{D} \rho_{1}}+\rho_{f} A_{D} \frac{\Delta Z_{1-2} g}{l_{1-2}} ;$

$\frac{d\left(W_{f_{3}}\right)}{d T}=\left(p_{2}-p_{3}\right) \frac{A_{T} g_{C}}{l_{2-3}} \frac{f\left(W_{f_{3}}\right)^{2}}{2 A_{T} D_{T} \rho_{f}}-\rho_{f} A_{T} g$

In the two-phase portions of the 10op, an additional term evaluating the force necessary to accelerate the fluid with mean density changes is added. The ratio of two-phase to single-phase frictional pressure drops in the net boiling portion of the test section is assumed to be

$$
\frac{\Delta P_{t \cdot p}}{\Delta P_{\text {s.p. }}}=1.3\left(\frac{1}{1-\bar{q}}\right)^{2}
$$

Figure $6^{(8)}$ shows the experimental basis for this assumption. 


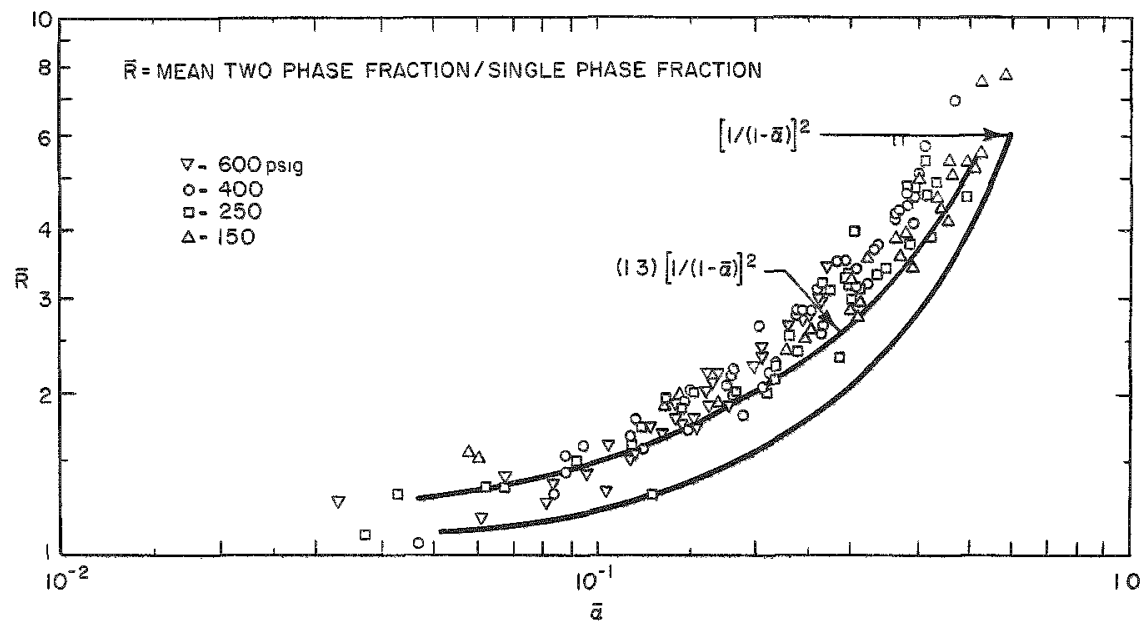

Fig. 6. Mean Two-phase Friction Multiplier vs. Steam Volume Fraction

In the adiabatic riser section, the two-phase to single-phase friction ratio is assumed $(9,10)$ to be

$$
\frac{\Delta P_{\text {t.p. }}}{\Delta P_{\text {s.p. }}}=\left(\frac{1}{1-\alpha}\right)^{2} \text {. }
$$

Thus, the momentum equations for the test section and riser are

$$
\begin{aligned}
\frac{d\left(\bar{W}_{3-4}\right)}{d T}= & \left(p_{3}-p_{4}\right) \frac{A_{T} g C}{\ell_{3-4}}-f \frac{\left(\bar{W}_{3-4}\right)^{2} \rho_{f}}{2 A_{T} D_{T}\left(\bar{\rho}_{3-4}\right)^{2}}-\bar{\rho}_{3-4} A_{T} g \\
& -\frac{A_{T}}{\ell_{3-4}}\left[\frac{W_{g_{4}}^{2}}{\alpha_{4} A_{T}^{2} \rho_{g}}+\frac{W_{f_{4}}^{2}}{\left(1-\alpha_{4}\right) A_{T}^{2} \rho_{f}}-\frac{W_{f_{3}}^{2}}{A_{T}^{2} \rho_{f}}\right]
\end{aligned}
$$

and

$$
\begin{aligned}
\frac{d\left(\bar{W}_{4-1}\right)}{d T}=\left(p_{4}-p_{1}\right) \frac{A_{R} g_{C}}{\ell_{4-1}}-f \frac{\left(\bar{W}_{4-1}\right)^{2}}{2 A_{R} D_{R}} \frac{\rho_{f}}{\left(\bar{\rho}_{4-1}\right)^{2}}-\bar{\rho}_{4-1} A_{R} g \\
-\frac{A_{R}}{\ell_{4-1}}\left[\frac{W_{g_{1}}^{2}}{\alpha_{1} A_{R}^{2} \rho_{g}}+\frac{W_{f_{1}}^{2}}{\left(1-\alpha_{1}\right) A_{R}^{2} \rho_{f}}-\frac{W_{g_{4}}^{2}}{\alpha_{4} A_{R}^{2} \rho_{g}}-\frac{W_{f_{4}}^{2}}{\left(1-\alpha_{4}\right) A_{R}^{2} \rho_{f}}\right]
\end{aligned}
$$

If it be assumed that the sum of the pressure changes around the 10op equals zero, the four equations of momentum conservation can be combined into a single equation giving the variation of total downcomer flow: 
17

$$
\begin{aligned}
\frac{d\left(W_{f_{2}}\right)}{d T}= & -\frac{A_{D} g C}{l_{1-2}}\left[\left(\frac{d W_{f_{2}}}{d \tau}+\rho_{f} A_{T} g+f \frac{W_{f_{2}}^{2}}{2 A_{T} D_{T} \rho_{f}}\right) \frac{\ell_{2-3}}{A_{T} g_{C}}\right. \\
& +\frac{l_{3-4}}{A_{T} g C}\left(\frac{d \bar{W}_{3-4}}{d \tau}+f \frac{\bar{W}_{3-4}^{2}}{2 D_{T} A_{T}} \frac{\rho_{f}}{\left(\bar{\rho}_{3-4}\right)^{2}}+\bar{\rho}_{3-4} A_{T g}\right. \\
& \left.+\frac{1}{l_{3-4}}\left\{\frac{W_{g_{4}}^{2}}{\alpha_{4} A_{T} \rho_{g}}+\frac{W_{f_{4}}^{2}}{\left(1-\alpha_{4}\right) A_{T} \rho_{f}}-\frac{W_{f_{3}}^{2}}{A_{T} \rho_{f}}\right\}\right) \\
& +\frac{l_{4-1}}{A_{R g C}}\left(\frac{d \bar{W}_{4-1}}{d T}+f \frac{\bar{W}_{4-1}^{2}}{2 D_{R} A_{R}} \frac{\rho_{f}}{\left(\bar{\rho}_{4-1}\right)^{2}}+\bar{\rho}_{4-1} A_{R g}+\frac{1}{l_{4-1}}\right. \\
& \left.\left.\left\{\frac{W_{g 1}}{\alpha_{1} A_{R} \rho_{g}}+\frac{W_{f_{1}}}{\left(1-\alpha_{1}\right) A_{R} \rho_{f}}-\frac{W_{g_{4}}^{2}}{\alpha_{1} A_{R} \rho_{g}}-\frac{W_{f_{4}}}{\left(1-\alpha_{4}\right) A_{R} \rho_{g}}\right\}\right)\right] \\
& +(f+K) \frac{W_{f_{2}}^{2}}{2 D_{D} A_{D} \rho_{f}}-\rho_{f} A_{D} \frac{z_{1-2}}{l_{1-2}} g
\end{aligned}
$$


A. Definition of Machine Variables

$$
\begin{aligned}
& W_{f_{1}}=a_{1} x_{1}, \quad \bar{\rho}_{3-4}=a_{13} x_{13}, \quad h_{2}=a_{22} x_{22} \\
& \mathrm{~W}_{\mathrm{f}_{2}}=\mathrm{W}_{\mathrm{f}_{3}}=\mathrm{a}_{3} \mathrm{x}_{3}, \quad \bar{\rho}_{4-1}=\mathrm{a}_{14} \mathrm{x}_{14}, \quad \alpha_{4}=\mathrm{a}_{27} \mathrm{x}_{27} \\
& \bar{W}_{3-4}=a_{4} x_{4}, \quad Q_{T}=a_{17} x_{17}, \quad W_{g_{1}}=a_{31} x_{31} \\
& \mathrm{~W}_{\mathrm{f}_{4}}=\mathrm{a}_{5} \mathrm{x}_{5}, \quad l_{2-3}=\mathrm{a}_{19} \mathrm{x}_{19}, \quad \alpha_{1}=\mathrm{a}_{33} \mathrm{x}_{33} \\
& \bar{W}_{4-1}=a_{6} x_{6}, \quad l_{3-4}=a_{20} x_{20}, \quad \tau_{4}=a_{34} x_{34} \\
& \mathrm{~W}_{\mathrm{g}_{4}}=\mathrm{a}_{7} \mathrm{x}_{7}, \quad \mathrm{~A}_{\mathrm{g}}=\mathrm{a}_{21} \mathrm{x}_{21}, \quad \mathrm{~S}=\mathrm{a}_{36} \mathrm{x}_{36} \\
& \mathrm{bt}=\tau \text {, }
\end{aligned}
$$

B. Assignment of Scale Factors
$a_{1}=1.0$
$a_{13}=10^{2}$
$a_{22}=10^{3}$
$a_{3}=1.0$
$a_{14}=10^{2}$
$a_{27}=10$
$a_{4}=1.0$
$a_{17}=10^{2}$
$a_{31}=10^{-1}$
$a_{5}=1.0$
$a_{19}=10$
$a_{33}=10$
$a_{6}=1.0$
$a_{20}=10$
$a_{34}=10^{2}$
$a_{7}=10^{-1}$
$a_{21}=10^{-2}$
$a_{36}=10$
$\mathrm{b}=1.0$

C. Machine Equations

$$
\begin{aligned}
& \frac{d x_{7}}{d t}=\frac{b a_{17} x_{17} x_{7}}{2 h_{f g} L_{T} \rho_{g} a_{21} x_{21}}-\frac{b a_{7} x_{7}^{2}}{2 a_{20} a_{21} \rho_{g} x_{20} x_{21}} \\
& x_{22}=\frac{h_{f}}{a_{22}}-\left(h_{f}-h_{m}\right) \frac{a_{31} x_{31}}{a_{3} a_{22} x_{3}} \\
& \frac{d x_{19}}{d t}=\frac{a_{3}^{2} b L_{T}}{a_{17} a_{19}^{2} A_{T} \rho_{f}}\left[\frac{x_{3}^{2}\left(h_{f}-a_{22} x_{22}\right)}{x_{17} x_{19}}\right]-\frac{a_{3} b x_{3}}{a_{19} A_{T} \rho_{f}}
\end{aligned}
$$




$$
\begin{aligned}
& \frac{d x_{13}}{d t}=\frac{b}{a_{13} a_{20} A T^{x_{20}}}\left(a_{3} x_{3}-a_{5} x_{5}-a_{7} x_{7}\right) \\
& x_{4}=\frac{0.5}{a_{4}}\left(a_{3} x_{3}+a_{5} x_{5}+a_{7} x_{7}\right) \\
& x_{5}=\frac{a_{7} \rho_{f} x_{7}}{a_{5} a_{27} a_{36} \rho_{g} x_{27} x_{36}}-\frac{a_{7} \rho_{f} x_{7}}{a_{5} a_{36} \rho_{g} x_{36}} \\
& x_{36}=\frac{c_{1}}{a_{36}}+\frac{a_{7}}{a_{36}}\left(\frac{c_{2} x_{7}}{a_{4} x_{4}}-\frac{c_{3} x_{7}}{\rho_{f} A_{T}}\right) \\
& x_{20}=\frac{L_{T}}{a_{20}}-\frac{a_{19}}{a_{20}} x_{19} \\
& x_{34}=\frac{a_{14} A_{R} L_{R} x_{14}}{a_{6} a_{34} x_{6}} \\
& x_{21}=\frac{a_{27} A_{T} x_{27}}{a_{21}} \\
& \frac{d x_{14}}{d t}=\frac{b}{a_{14} A_{R} L_{R}}\left(a_{7} x_{7}+a_{5} x_{5}-a_{1} x_{1}-a_{31} x_{31}\right) \\
& x_{27}=\frac{c_{4}}{a_{27}}-\frac{a_{13} c_{4} x_{13}}{a_{27} \rho_{f}} \\
& x_{6}=\frac{0.5}{a_{6}}\left(a_{7} x_{7}+a_{5} x_{5}+a_{31} x_{31}+a_{1} x_{1}\right) \\
& x_{33}=\frac{2.0-c_{4}}{a_{33}}-\frac{2 a_{14} x_{14}}{a_{33} \rho_{f}}+\frac{a_{13} c_{4} x_{13}}{a_{33} \rho_{f}} \\
& x_{1}=\left(\frac{a_{31} \rho_{f}}{a_{1} a_{33} a_{36} \rho_{g}}\right) \frac{x_{31}}{x_{33} x_{36}}-\left(\frac{a_{31} \rho_{f}}{a_{1} a_{36} \rho_{g}}\right) \frac{x_{31}}{x_{36}}
\end{aligned}
$$




$$
\begin{aligned}
& -\frac{d x_{3}}{d t}\left(1.0+\frac{a_{19} A_{D x_{19}}}{A_{T} l_{1-2}}\right)=\frac{a_{3} a_{19} b A_{D} f_{3}^{2} x_{19}}{l_{1-2} \cdot 2 A_{T} \cdot D_{T} \rho_{f}}+\frac{a_{3} b(f+K) x_{3}^{2}}{2 D D A D f_{f}}-\frac{a_{3} b A_{D} x_{3}^{2}}{A_{T} \cdot l_{1-2} \cdot A_{T} \cdot f_{f}} \\
& +\frac{a_{4}^{2} a_{20} b A_{D} \cdot f \rho_{f} x_{4}^{2} x_{20}}{a_{3} a_{13}^{2} A_{T} l_{1-2} 2 D T A T x_{13}^{2}}+\frac{a_{6}^{2} b A_{D} l_{4-1} f \rho_{f} x_{6}^{2}}{a_{3} a_{14}^{2} A_{R} l_{1-2} 2 D R A_{R} x_{14}^{2}} \\
& +\frac{a_{14} a_{20} b_{D A g x} x_{14} x_{20}}{a_{3} l_{1-2}}+\frac{a_{14} b_{D} l_{4-1} g x_{14}}{a_{3} l_{1-2}}+\frac{a_{19} b_{D D} A_{f} g x_{19}}{a_{3} l_{1-2}} \\
& +\frac{a_{31}^{2} b A_{D}^{x_{31}^{2}}}{a_{3} a_{33} l_{1-2} A_{R}^{2} \rho_{g} x_{33}}+\frac{a_{1}^{2} b A_{D x_{1}}^{2}}{a_{3} l_{1-2} A_{R}^{2} \rho_{f}\left(1-a_{31} x_{31}\right)} \\
& +\left(\frac{a_{4} a_{20} x_{20}}{a_{3} A{ } l_{1-2}}\right) \frac{d x_{4}}{d t}+\left(\frac{a_{6} A_{D} l_{4-1}}{a_{3} A R \ell_{1-2}}\right) \frac{d x_{6}}{d t} \\
& -\frac{b \rho_{f} A_{D} Z_{1-2 g}}{a_{3} l_{1-2}}
\end{aligned}
$$

D. Values of Constants and Initial Conditions

Table 1

I-in. geometry, 600 psig

$$
\begin{aligned}
& A D=2.33 \times 10^{-2} \mathrm{ft}^{2} \quad \mathrm{f}=0.0155 \\
& A_{R}=4.79 \times 10^{-3} \mathrm{ft}^{2} \quad \mathrm{f}+\mathrm{K}=0.261 \\
& \ell_{4-1}=3.5 \mathrm{ft} \\
& A_{T}=4.79 \times 10^{-3} \mathrm{ft}^{2} \\
& g=32.2 \mathrm{ft} / \mathrm{sec}^{2} \\
& \mathrm{C}_{1}=1.3 \\
& \mathrm{~h}_{\mathrm{f}}=474.7 \mathrm{Btu} / \mathrm{lb} \\
& \mathrm{C}_{2}=22.8 \\
& \mathrm{~h}_{\mathrm{g}}=1203 \mathrm{Btu} / \mathrm{lb} \\
& \mathrm{LT}_{\mathrm{T}}=3.0 \mathrm{ft} \\
& \mathrm{C}_{3}=3.0 \\
& h_{f g}=728.3 \mathrm{Btu} / \mathrm{lb} \\
& C_{4}=1.6 \\
& \mathrm{~h}_{\mathrm{m}}=60 \mathrm{Btu} / \mathrm{lb} \\
& D_{D}=0.17225 \mathrm{ft} \\
& l_{1-2}=16.67 \mathrm{ft} \\
& p_{\mathrm{f}}=49.50 \mathrm{lb} / \mathrm{ft}^{3} \\
& \rho_{\mathrm{g}}=1.333 \mathrm{lb} / \mathrm{ft}^{3} \\
& D_{R}=0.0781 \mathrm{ft} \\
& \mathrm{D}_{\mathrm{T}}=0.0781 \mathrm{ft} \\
& Q_{T}(0)=54.0 \mathrm{kw} \text {, } \\
& \mathrm{W}_{\mathrm{f}_{3}}(0)=0.947 \mathrm{lb} / \mathrm{sec} \text {, } \\
& \bar{\rho}_{4-1}(0)=23.8 \mathrm{lb} / \mathrm{ft}^{3} \\
& \bar{\rho}_{3-4}(0)=33.4 \mathrm{Ib} / \mathrm{ft}^{3} \text {, } \\
& \ell_{2-3}(0)=1.089 \mathrm{ft} \\
& \mathrm{W}_{g_{4}}=0.0461 \mathrm{lb} / \mathrm{sec} \text {. }
\end{aligned}
$$


Table 2

1-in. geometry, 300 psig

\begin{tabular}{|c|c|c|}
\hline$A_{D}=2.33 \times 10^{-2} \mathrm{ft}^{2}$ & $D_{R}=0.0781 \mathrm{ft}$ & $\mathrm{h}_{\mathrm{m}}=60 \mathrm{Btu} / \mathrm{lb}$ \\
\hline$A R=4.79 \times 10^{-3} \mathrm{ft}^{2}$ & $D_{T}=0.0781 \mathrm{ft}$ & $l_{1-2}=16.67 \mathrm{ft}$ \\
\hline$A_{T}=4.79 \times 10^{-3} \mathrm{ft}^{2}$ & $f=0.0155$ & $l_{4-1}=3.5 \mathrm{ft}$ \\
\hline$C_{1}=1.63$ & $f+K=0.261$ & $L_{T}=3.0 \mathrm{ft}$ \\
\hline$C_{2}=34.2$ & $g=32.2 \mathrm{ft} / \mathrm{sec}^{2}$ & $p_{\mathrm{f}}=52.63 \mathrm{lb} / \mathrm{ft}^{3}$ \\
\hline $\mathrm{C}_{3}=4.85$ & $h_{f}=398.8 \mathrm{Btu} / 1 \mathrm{~b}$ & $\rho_{\mathrm{g}}=0.6798 \mathrm{Ib} / \mathrm{ft}^{3}$ \\
\hline$C_{4}=1.6$ & $\mathrm{~h}_{\mathrm{g}}=1203.2 \mathrm{Btu} / \mathrm{lb}$ & $Z_{1-2}=6.42 \mathrm{ft}$ \\
\hline $\mathrm{D}_{\mathrm{D}}=0.17225 \mathrm{ft}$ & $\mathrm{h}_{\mathrm{fg}}=804.4 \mathrm{Btu} / \mathrm{lb}$ & \\
\hline$Q_{T}(0)=46.0 \mathrm{kw}$ & $\mathrm{W}_{\mathrm{f}_{3}}(0)=0.830 \mathrm{Ib} / \mathrm{sec}$ & $\bar{\rho}_{4-1}(0)=19.75 \mathrm{Ib} / \mathrm{ft}^{3}$ \\
\hline $\bar{\rho}_{3-4}(0)=32.2 \mathrm{lb} / \mathrm{ft}^{3}$ & $\ell_{2-3}(0)=0.846 \mathrm{ft}$ & $W_{g_{4}}(0)=0.039351 \mathrm{~b} / \mathrm{sec}$ \\
\hline
\end{tabular}

E. Analog Circuit Diagram

See following Figure 7 . 


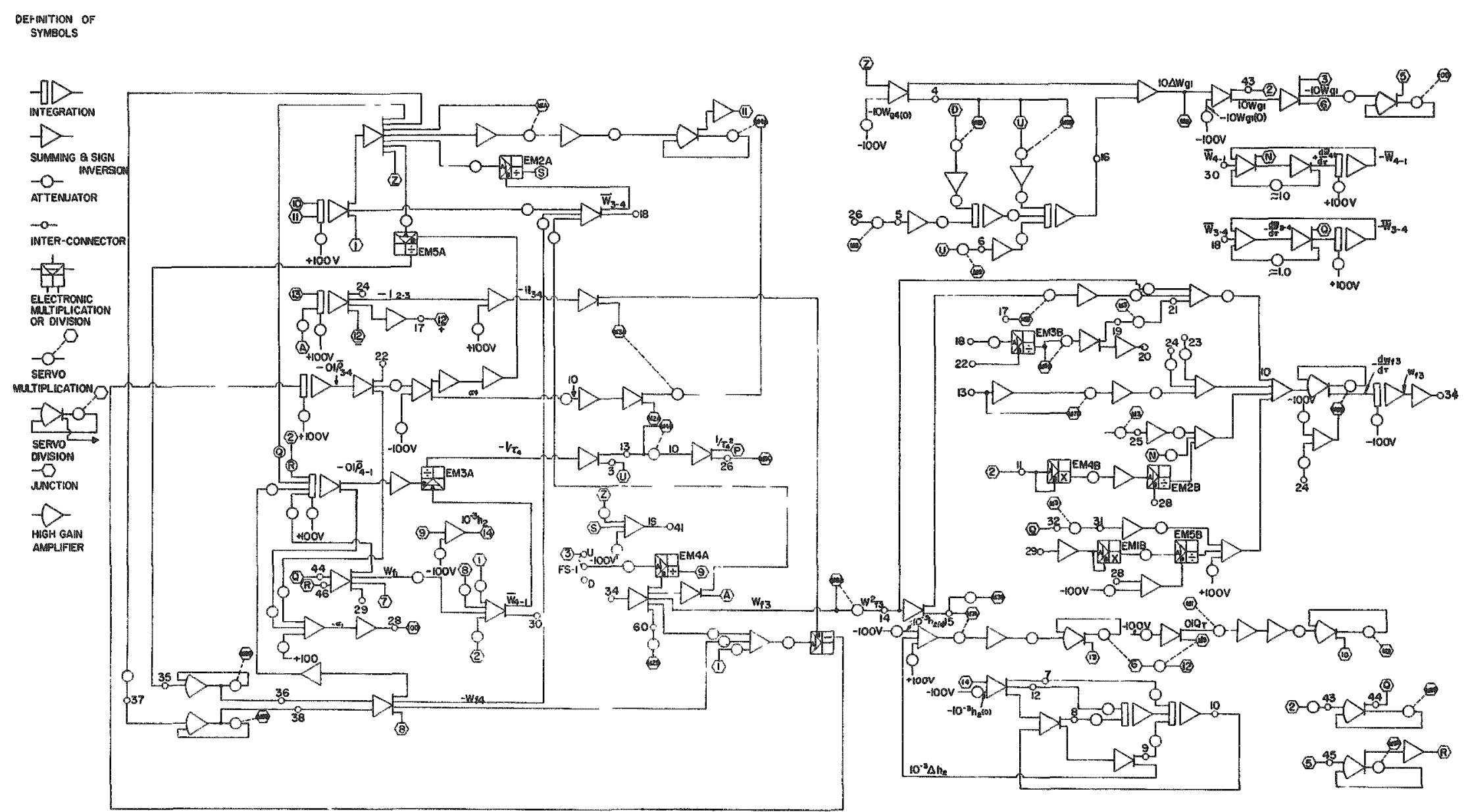

Fig. 7. Analog Circuit Diagram 
F. Potentiometer Settings

(1) 1-in. geometry, 600 psig.

The following table gives the potentiometer settings for the "Armadilla" 1-in. geometry at 600 psig. 
Table 3

Argome Rational Laboracom

APPLIED MATHEMATICS DIVISION

ANALOG COMPUTER

POTENTIOMETER SETTINGS

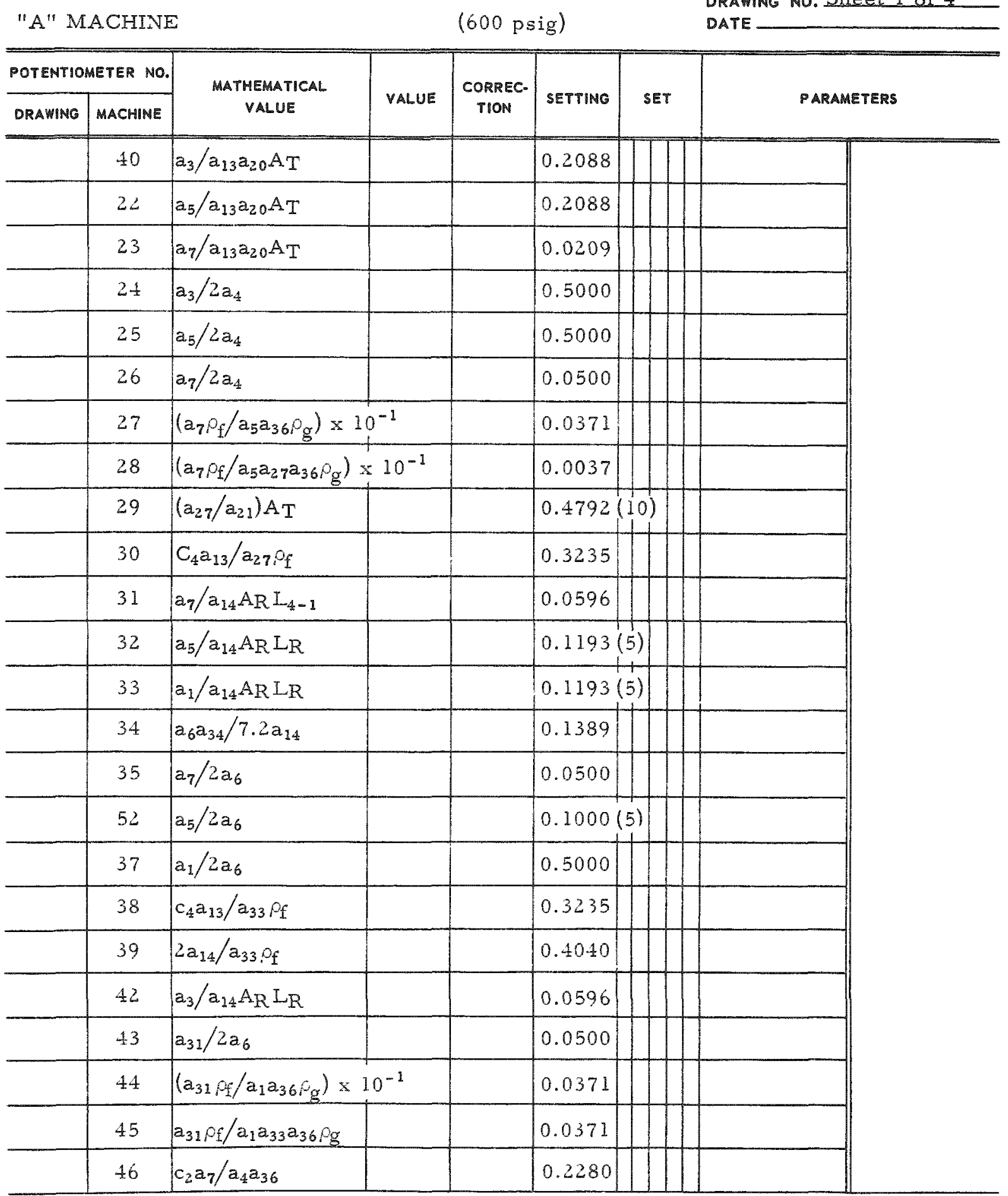

PROBLEM NO. 1287/RE DRAWING NO. Sheet 1 of 4 DATE 
Argonn Rational Laboratov

APPLIED MATHEMATICS DIVISION

ANALOG COMPUTER

POTENTIOMETER SETTINGS

"A" MACHINE

(600 psig)

PROBLEM NO. $1287 / \mathrm{RE}$

DRAWING NO. Sheet 2 of 4

DATE



AMD.2C $(0.57)$ 


\section{Argonne Rational Iaboratoru \\ APPLIED MATHEMATICS DIVISION \\ AMALOG COMPUTER \\ POTENTIOMETER SETTINGS}



$A .2 C(8.57)$ 
Zrgome Racional Laboracom

APPLIED MATHEMATICS DIVISION

AMALOG COMPUTER

POTENTIOMETER SETTINGS

"B" MACHINE

(600 psig)
PROBLEM NO. $1287 / R E_{1}$ DRAWING NO. Sheet 4 of 4 DATE

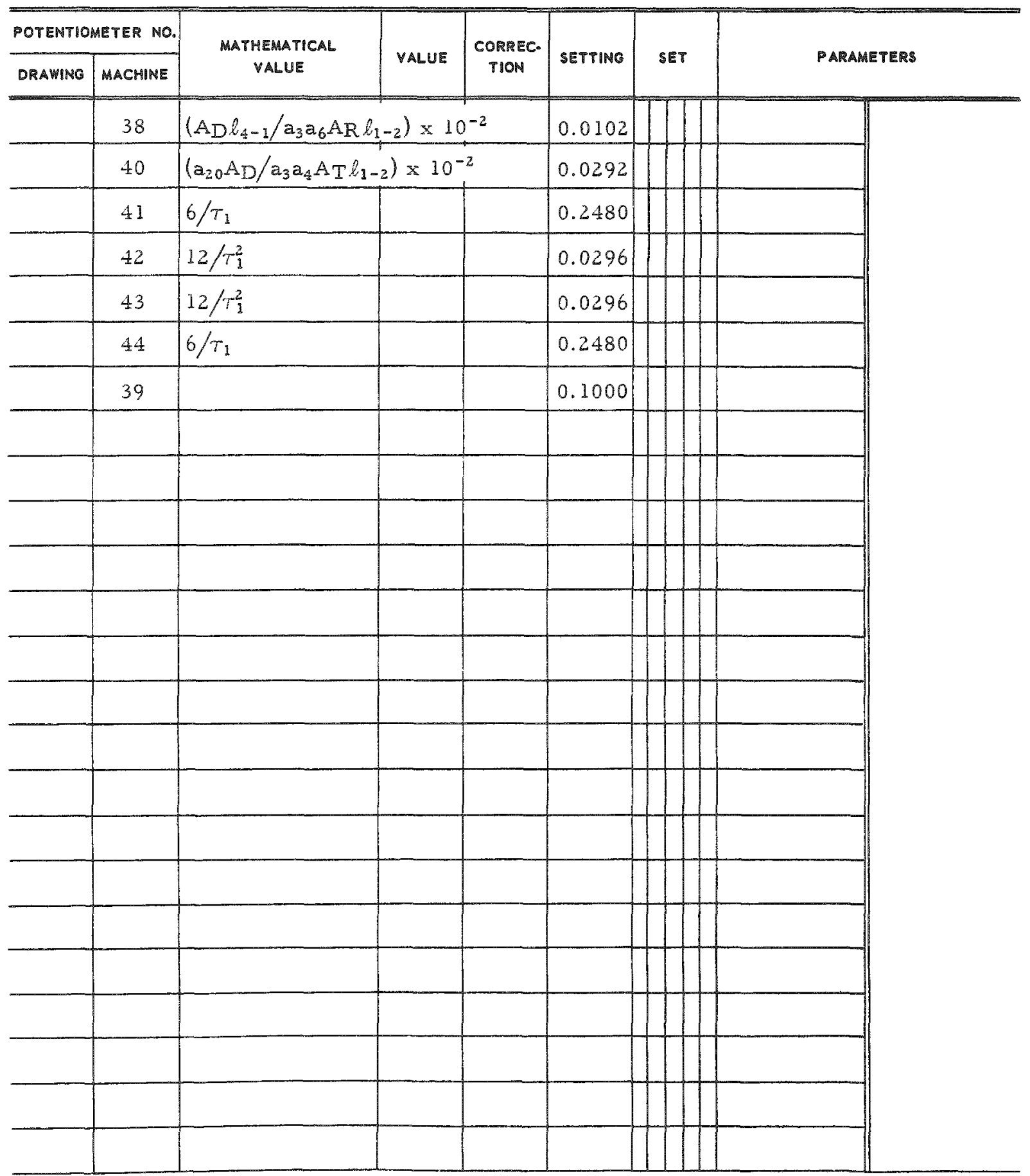


(2) 1-in. geometry, 300 psig

The necessary potentiometer changes for a pressure change to 300 psig are shown in Table 4. 
Table 4

\section{Argent Rational Laborator \\ APPLIED MATHEMATICS DIVISION \\ ANALOG COMPUTER \\ POTENTIOMETER SETTINGS}

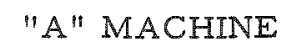

(300 psig)

PROBLEM NO. $1287 / R E$

DRAMING NO. Sheet 1 of 3

DATE

\begin{tabular}{|c|c|c|c|c|c|c|c|}
\hline \multicolumn{2}{|c|}{ POTENTIOMETER NO. } & \multirow{2}{*}{$\begin{array}{l}\text { MATHEMATICAL } \\
\text { VALUE }\end{array}$} & \multirow{2}{*}{ VALUE } & \multirow{2}{*}{$\begin{array}{l}\text { CORREC- } \\
\text { TION }\end{array}$} & \multirow{2}{*}{ SETTING } & \multirow{2}{*}{ SET } & \multirow{2}{*}{ PARAMETERS } \\
\hline DRAWING & MACHINE & & & & & & \\
\hline & 27 & \multicolumn{2}{|c|}{$\left(a_{7} \rho_{f} / a_{5} a_{36} \rho_{g}\right) \times 10^{-1}$} & & 0.0774 & & \\
\hline & 28 & \multicolumn{2}{|c|}{$\left(a_{7} \rho_{\mathrm{f}} / a_{5} a_{27} a_{36} \rho_{\mathrm{g}}\right) \times 10^{-1}$} & & 0.0077 & & \\
\hline & 30 & $\mathrm{C}_{4} \mathrm{a}_{13} / \mathrm{a}_{27} \rho_{\mathrm{f}}$ & & & 0.3040 & & \\
\hline & 38 & $C_{4} a_{13} / a_{33} \rho_{f}$ & & & 0.3040 & & \\
\hline & 39 & $2 a_{14} / a_{33} \rho_{f}$ & & & 0.3800 & & \\
\hline & 44 & \multicolumn{2}{|c|}{$\left(a_{31} \rho f / a_{1} a_{36} \rho_{g}\right) \times 10^{-1}$} & & 0.0774 & & \\
\hline & 45 & $a_{31} \rho f / a_{1} a_{33} a_{36} \rho g$ & & & 0.0774 & & \\
\hline & 46 & $C_{2} a_{7} / a_{4} a_{36}$ & & & 0.2930 & & \\
\hline & 47 & $\left(h_{f}-h_{m}\right) a_{31} / a_{3} a_{22}$ & & & 0.0339 & & \\
\hline & 48 & $a_{7} / 2 a_{20} a_{21} \rho g$ & & & \multicolumn{2}{|c|}{$0.0736(10)$} & \\
\hline & 49 & $a_{17} / 2 a_{21} h_{f g} L_{T} \rho_{g}$ & & & \multicolumn{2}{|c|}{$0.3367(10)$} & \\
\hline & 50 & $L_{\mathrm{T}} / \mathrm{A}_{\mathrm{T}} \rho_{\mathrm{f}} \mathrm{a}_{19}$ & & & \multicolumn{2}{|c|}{$0.1190(10) \mid$} & \\
\hline & 51 & $C_{3} a_{7} / a_{36} P_{f} A_{T}$ & & & 0.1190 & & \\
\hline & 54 & $a_{3} / a_{19} A_{T} \rho_{f}$ & & & 0.3967 & & \\
\hline & 5 & $Q_{T}(0) / a_{17}$ & & & 0.4600 & & \\
\hline & 6 & $h_{1} / a_{22}$ & & & 0.3988 & & \\
\hline & 7 & $l_{2-3}(0) / a_{19}$ & & & 0.8460 & & \\
\hline & 8 & $\bar{\rho}_{3-4}(0) / a_{13}$ & & & 0.3220 & & \\
\hline & 10 & $\bar{\rho}_{4}-1(0) / a_{14}$ & & & 0.1975 & & \\
\hline & 11 & $w_{g_{4}}(0) / a_{7}$ & & & 0.3935 & & \\
\hline & 12 & $\mathrm{ICx}_{22}$ & & & & & \\
\hline & 13 & $\mathrm{ICx}_{22}$ & & & & & \\
\hline & 14 & $\mathrm{ICx}_{7}$ & & & & & \\
\hline & 15 & $\mathrm{ICx}_{7}$ & & & & & \\
\hline
\end{tabular}


Ergunne Aational Lahoraton

APPLIED MATHEMATICS DIVISION

ANALOG COMPUTER

POTENTIOMETER SETTINGS

PROBLEM NO. $1287 / \mathrm{RE}$

DRAWING NO. Sheet 2 of 3

"A" MACHINE

(300 psig)

DATE

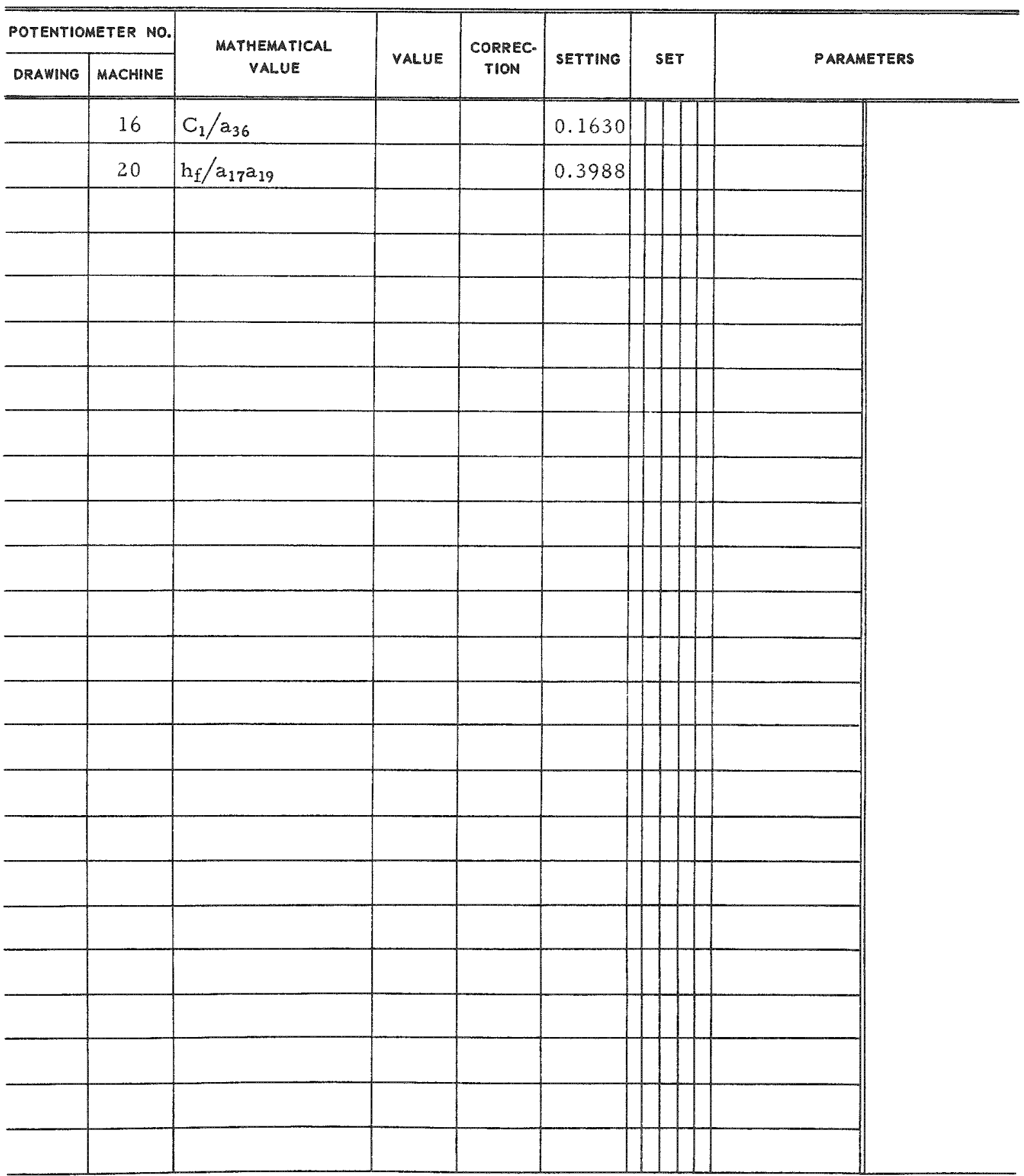

Aพจ $.2 \mathrm{C}(8.57)$ 
Argone Rational Caboratoru

APPLIED MATHEMATICS DIVISION

ANALOG COMPUTER

POTENTIOMETER SETTINGS

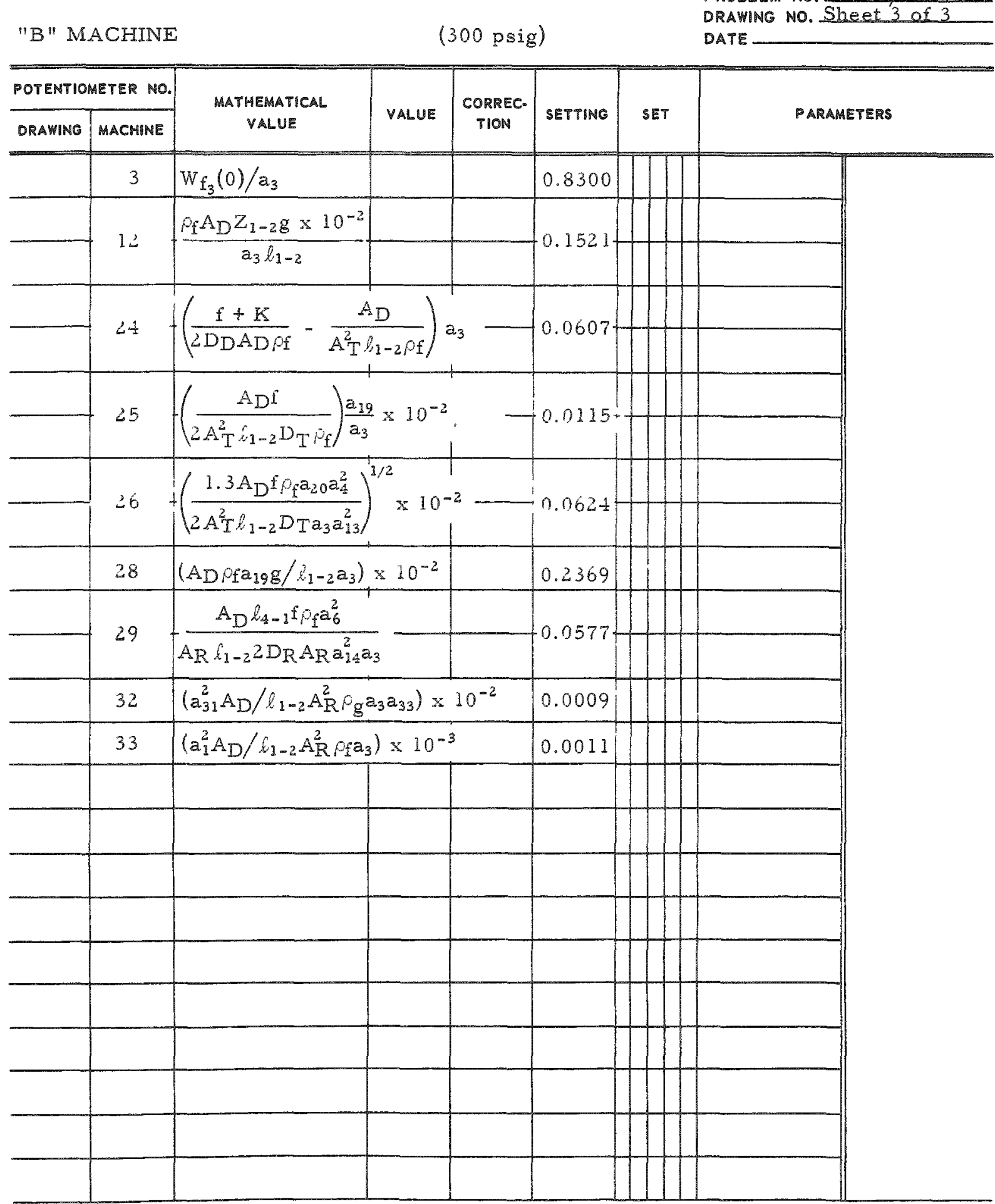

DRAWING NO. Sheet 3 of

DATE
PROBLEM NO. I287/RE 


\section{COMPARISON OF MODEL PERFORMANCE WITH EXPERIMENTAL DATA}

The comparison of the performance of the analog model with the experimental test loop is presented in graphical form. During the development and testing of the model many graphs were made. Representative comparisons are presented in the following sections.

A. Steady-state Comparison

The steam void fraction at the test section exit and the total recirculation flow rateare shown as functions of power input in Figs. 8, 9, and 10 .
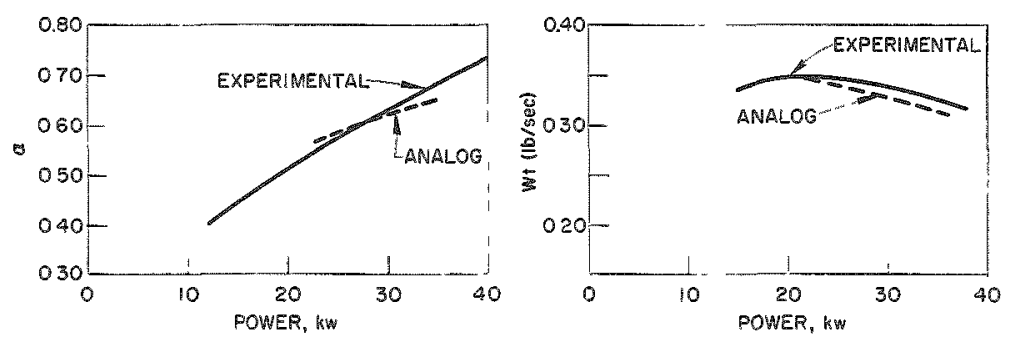

Fig. 8. Comparison of Experimental Data with Analog Model for the Following:

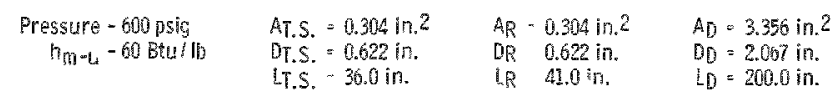


Fig. 9. Comparison of Experimental Data with Analog Model for the Following:

\begin{tabular}{|c|c|c|}
\hline $\begin{array}{l}\text { ressure - } 500 \text { psig } \\
h_{\Gamma \mathrm{T}}-60 \text { Btuliti }\end{array}$ & $\begin{array}{l}\text { AT.S. }=0.304 \mathrm{in}^{2} \\
\text { DT.S. }=0.622 \mathrm{in} \\
\text { LT.S. }=36.0 \mathrm{in} .\end{array}$ & $\begin{array}{l}A R=0.304 \mathrm{in.}^{2} \\
D R=0.622 \mathrm{in} . \\
L R=41.0 \mathrm{in} .\end{array}$ \\
\hline
\end{tabular}
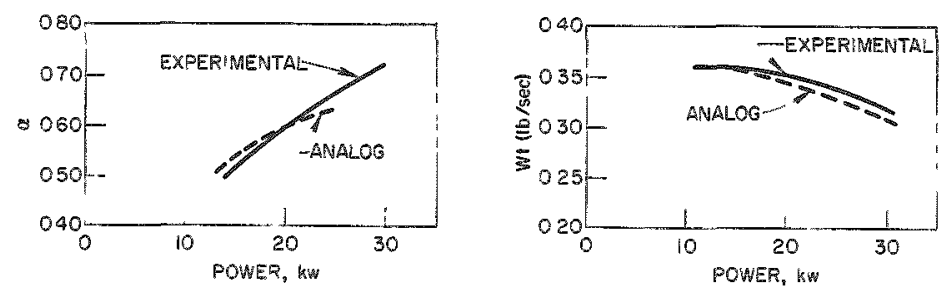

Fig. 10. Comparison of Experimental Data with Analog Model for the Following Conditions: 
In general, the total flow-rate curve is slightly low $(2-5 \%)$, but the slope of the curve, which seems intuitively more important, compares very well with the prediction.

B. Oscillatory Power

Few experimental points with sinusoidal power variations are available. Comparison of the analog with one of the se points is shown in Fig. 11.

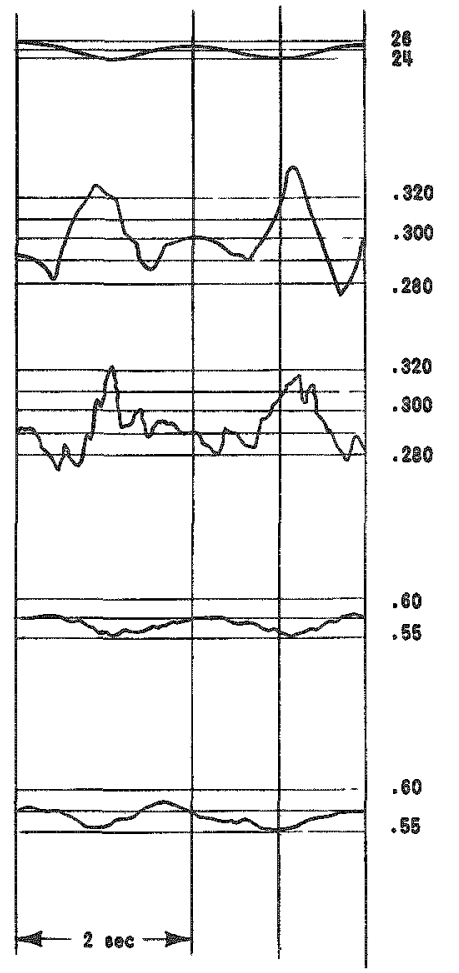

POWER(kW)

EXPERI MAEMTAL FLOW RATE

$(16 / 00)$

AMALOG FLOW RATE

(16/8)

EXPEQ MENTAL STEAM YOLUAE FRACTIOH

AHALOO STEAM พOLUME PRABT OH
Fig. 11

Transient Comparison Between Analog Model and Experimental Measurements

C. Unstable Power Levels

The powers at which the analog model began to oscillate and overload are compared with experimental points of lowest oscillatory power in Fig. 12 .

In addition to the above unrestricted runs, an attempt was made to investigate the effect of simulating riser and downcomer restrictions in the analog model.

Since the steady-state losses through an orifice in single-phase flow are directly proportional to the velocity head, the downcomer restriction was simulated by increasing the downcomer friction factor.

The actual restriction in the experimental loop is a valve with an unmeasured loss coefficient, making it impossible to evaluate the required 
increase in friction factor. This was overcome by increasing the friction factor in the analog model with the model operating at steady state. When the analog recirculation rate decreased by the same fraction as in the experimental loop, it was assumed that the orifice was correctly simulated.

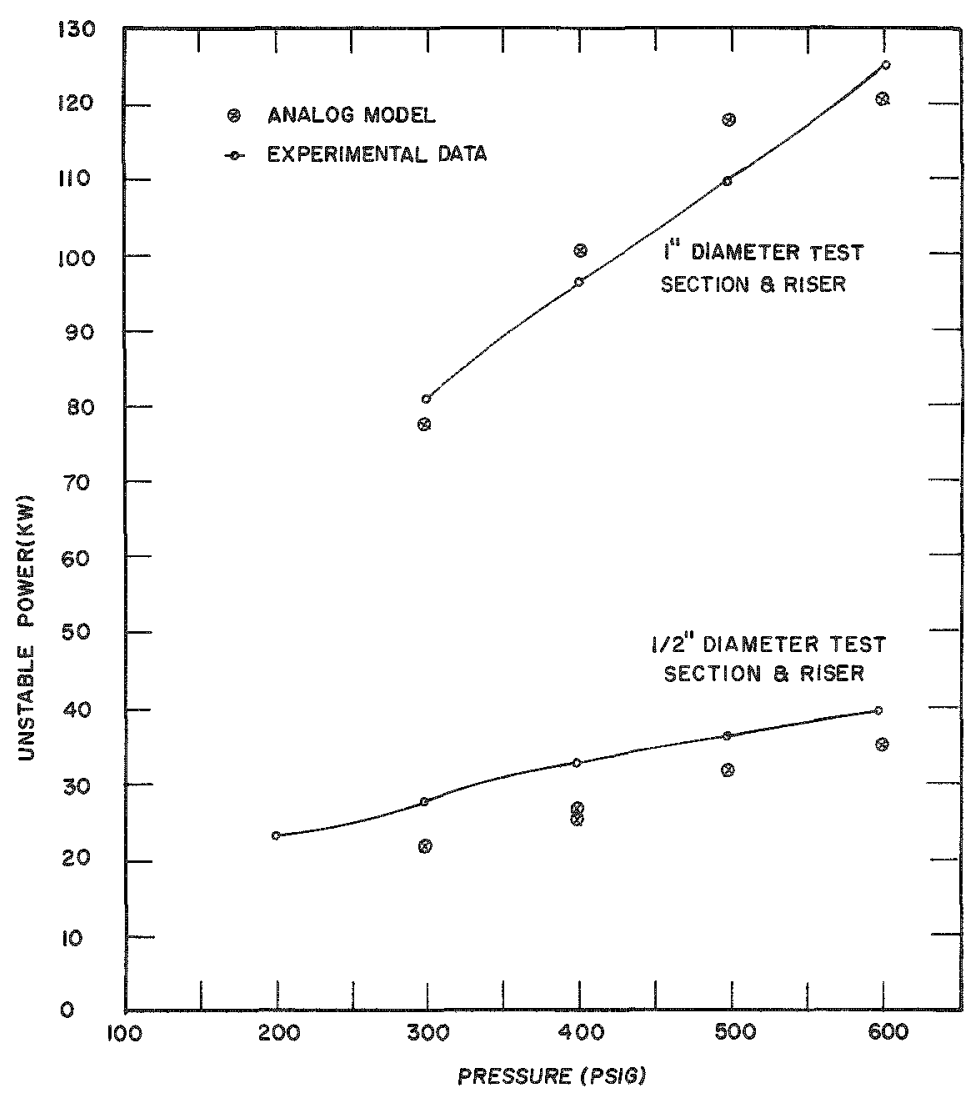

Fig. 12

Comparison of Predicted and Measured Power at the Inception of Oscillation

Assuming that all losses occur in the flowing liquid phase and the void fraction remains constant, it can be shown(11) that the steady-state losses across an orifice in a two-phase region are directly proportional to the velocity head and to the two-phase friction factor $R$ as evaluated in the model:

$$
\Delta P_{10 s s} \sim \frac{V^{2}}{2 g} \frac{1}{(1-\alpha)^{2}}
$$

But this is the form of the riser friction term in the momentum equation. Therefore, the orifice was simulated by changing the coefficient corresponding to the riser friction factor.

As with the downcomer restriction, the change in the coefficient was determined by the resultant change in total recirculation rate.

The analog restriction simulations were run with the 1 -in. geometry at $300 \mathrm{psig.} \mathrm{The} \mathrm{results} \mathrm{are} \mathrm{tabulated} \mathrm{in} \mathrm{Table} 5$. The $4 \mathrm{kw}$ heat loss correction has been added to the analog unstable power values. 
Table 5

Comparison of Unstable Power Levels (1-in. geometry, 300 psig)

Type Restriction

Analog

Unstable Power

$(\mathrm{kw})$

Unrestricted

Low Downcomer Restriction

High Downcomer Restriction

Low Riser Restriction
Experimental

Unstable Power

$(\mathrm{kw})$

$\begin{array}{ll}80 & 81 \\ 76 & 82 \\ 69 & 90 \\ 67 & 65\end{array}$

Clearly the riser orifice was correctly simulated. A possible cause of the discrepancies in the downcomer restriction is in the assumption that evaluation of the steady-state loss is adequate for the model. For measuring pulsating flow with an orifice it is recommended(12) that steady-state solutions be applied only when the Strouhal number is less than 0.002 . The Strouhal number, which gives an indication of the relative importance of the acceleration due to flow variation with time and the acceleration due to flow variation with pipe location, has the following form:

$$
N_{S}=D_{f} / V \quad,
$$

where $D$ is the orifice diameter, $f$ is frequency, and $V$ is average flow velocity. The Strouhal number for the downcomer restriction is 0.21 . For the riser orifice it is 0.0023 .

Possibly the incorrect evaluation of the large time-dependent acceleration in the downcomer caused the incorrect trend in the analogmodel. 


\section{FURTHER RESULTS}

Since the model is capable of predicting the transient loop behavior, the model was dismantled, and the effect of each alteration on the power at inception of oscillations was noted. A particular geometry and pressure condition was selected as standard, and the model performance was compared with the standard after each change.

(1) From the standard, the correct slip ratio at the initial relatively low power, the rate of increase of slip ratio with power, and the slip ratio at maximum stable power were determined. Four alternate models of slip dependence on power were tested. The results are shown. in Fig. 13. In cases 1 and 2, slip ratio is too low at the normal oscillatory power, and the model became unstable at a lower power level. Note that the model oscillated at the correct power in cases 3 and 4 . The se results indicate that the model is sensitive to the magnitude of the slip ratio, but insensitive to the rate of change of slip ratio with power.

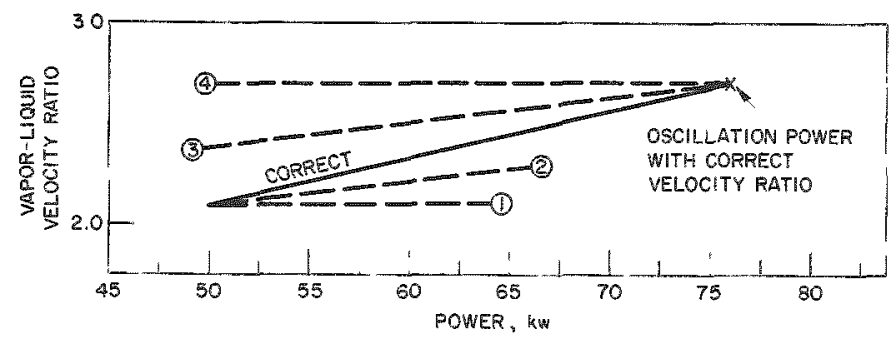

Fig. 13. Alternate Models of Velocity Ratio as a Function of Power

(2) The time lag between changes of enthalpy (due to either flow or temperature variation) at the makeup point and at the inlet to the test section was computed from the total flow rate and the downcomer geometry. The power level at oscillation was unaffected when the lag was increased, decreased, or completely eliminated from the model.

(3) The combined momentum equation (Eq. II.26) has two terms containing derivatives. These terms account for the variation in acceleration of the two-phase pressure drop when the mean test section and riser mass flow rates vary. Therefore, only a small correction to a part of the overall two-phase pressure drop is contributed by the se derivatives.

Since differentiation is a noise-amplifying system, it was thought that the derivatives would influence the model. The effect of eliminating the derivatives was studied. Individual and collective elimination of these terms from the system had no effect on the oscillatory power level. 
(4) It was previously stated that the time lag of a void change traversing up the riser was calculated by assuming the void change moves upward with the local liquid velocity. Six variations of this time lag were tested. The lag was multiplied by $0,0.75,1.0,1.33,1.5$, and 2.0 , and the unstable power level for each case measured. The dependence of unstable power on this lag is shown in Fig. 14.

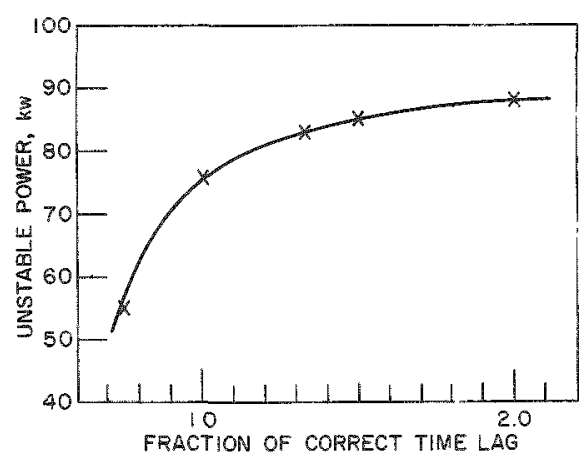

Fig. 14. Dependence of Unstable Power on Riser Time Lag 


\section{GENERAL DISCUSSION AND CONCLUSIONS}

It has been hypothesized that a change of flow pattern somewhere within the loop causes a discontinuous change in steam-water distribution and pressure drop. These effects feed back into the loop dynamics, causing a reversion to the original flow pattern, which causes the loop to oscillate. It may be true that loops of different geometries oscillate from different basic causes. Therefore, we cannot rule out the hypothesis.

The hypothesis, clearly, does not apply to the loop presented herein, since the model properly predicts the transient behavior and oscillatory power level with the use of two-phase friction and void fraction correlations with no discontinuities.

The two-phase pressure-drop and void-fraction correlations used in this model were originally derived from steady-state data. Within the frequency range considered (the loop oscillated in the period range of $1.0-1.5 \mathrm{sec} /$ cycle), these correlations do an adequate job.

Continued effort to obtain a simple physical model with an attendant stability correlation is deemed worthwhile. The complexity of a complete model makes it difficult to apply in the design stages of a reactor project.

It is hoped that knowledge of the relative importance of the individual components of the system herein, and other models, will soon lead to simple, useable stability criteria.

\section{ACKNOWLEDGEMENTS}

The authors gratefully acknowledge the advice and assistance of Mr. N. F. Morehouse, Jr., of the Applied Mathematics Division, and Mr. Frank J. Maletich for machine maintenance and calculations. 


\section{BIBLIOGRAPHY}

1. Wissler, E. H., Isbin, H. S., and Amundson, N. R., The Oscillatory Behavior of a Two-phase Natural Circulation Loop, A.I. Ch.E. J., 2(No. 2) (June 1956).

2. Quandt, E. R., The Analysis and Measurement of Flow Oscillations, Chemical Engineering Progress Symposium Series, No. 32, p. Ill (1961).

3. Levy, S., and Beckjord, E. S., Hydraulic Instability in a Natural Circulation Loop with Net Steam Generation at 1000 psia, GEAP 3215 (July 1959).

4. Asyee, J., Summary of an Experimental Investigation of the Heatremoval of the First Fuel-charge of the HBWR, Halden Internal Report HIR-11 (May 1959).

5. Anderson, R. P., and Lottes, P. A., "Boiling Stability," Ch. 1, in Progress in Nuclear Energy, Series 4, Vol. 4, C. M. Nicholls, Ed. London, Pergamon Press (1961).

6. Garlid, K., Amundson, N. R., and Isbin, H. S., A Theoretical Study of the Transient Operation and Stability of Two-phase Natural Circulation Loops, ANL-6381 (1961).

7. Marchaterre, J. F., and Hoglund, B. M., Velocity Ratios in Vertical Two-phase Flow, Nucleonics (Aug 1962).

8. Hoglund, B. M., Weatherhead, R. J., and Epperson, T.R., Two-phase Pressure Drop in Natural-circulation Boiling Channel, ANL-5760 (1961).

9. Richardson, B. L., Some Problems in Horizontal Two-phase Twocomponent Flow, ANL-5949 (1960).

10. Lottes, P. A., et al., Experimental Studies of Natural Circulation Boiling and Their Application to Boiling Reactor Performance, Second United Nations International Conference on Peaceful Uses of Atomic Energy, Geneva, Switzerland, 7, 784 (1958).

11. Lottes, P. A., Personal Communication.

12. Oppenheim, A. K., and Chilton, E. G., Pulsating-flow Measurement A Literature Search, Trans. of ASME, 77 (2), 231 (1955). 